\title{
ERRATUM
}

\section{LMIP/AAA: Local Authentication, Authorization and Accounting (AAA) Protocol for Mobile IP}

\author{
Manel Chenait \\ Laboratoire des Systemes Informatiques, LSI, USTHB \\ BP n32 El Alia, Bab Ezzaouar, 16111, Algiers, Algeria \\ fchenaitg@gmail.com
}

H. Jahankhani, K. Revett, and D. Palmer-Brown (Eds.): ICGeS 2008, CCIS 12, pp. 228-238, 2008.

(C) Springer-Verlag Berlin Heidelberg 2008

\section{DOI 10.1007/978-3-540-69403-8_36}

In the original version, the author Manel Chenait's email address is incorrect. The correct email address is as follows:

\section{Manel Chenait}

Laboratoire des Systemes Informatiques, LSI, USTHB

BP n32 El Alia, Bab Ezzaouar, 16111, Algiers, Algeria

chenait@gmail.com

The original online version of this chapter can be found at http://dx.doi.org/10.1007/978-3-540-69403-8_27 